\title{
Stage IVA Oropharyngeal Undifferentiated Carcinoma AJCC v7
}

\author{
National Cancer Institute
}

\section{Source}

National Cancer Institute. Stage IVA Oropharyngeal Undifferentiated Carcinoma A/CC v7. NCI Thesaurus. Code C115090.

Stage IVA includes: (T4a, N0, M0); (T4a, N1, M0); (T1, N2, M0); (T2, N2, M0); (T3, N2, M0); (T4a, N2, M0). T4a: T umor with moderately advanced local disease. T umor invades the larynx, extrinsic muscle of tongue, medial pterygoid, hard palate, or mandible. Mucosal extension to lingual surface of epiglottis from primary tumors of the base of the tongue and vallecula does not constitute invasion of larynx. T1: T umor $2 \mathrm{~cm}$ or less in greatest dimension. T2: Tumor more than $2 \mathrm{~cm}$ but not more than $4 \mathrm{~cm}$ in greatest dimension. T3: Tumor measuring more than 4 centimeters in greatest dimension or extension to lingual surface of epiglottis. N0: No regional lymph node metastasis. N1: Metastasis in a single ipsilateral lymph node, $3 \mathrm{~cm}$ or less in greatest dimension. N2: Tumor with metastasis in a single ipsilateral lymph node, more than $3 \mathrm{~cm}$ but not more than $6 \mathrm{~cm}$ in greatest dimension, or in multiple ipsilateral lymph nodes, none more than 6 $\mathrm{cm}$ in greatest dimension, or in bilateral or contralateral lymph nodes, none more than 6 $\mathrm{cm}$ in greatest dimension. M0: No distant metastasis. (AJCC 7th ed.) 